\title{
Hedging the Brazilian stock index in the era of low interest rates: What has changed?
}

\author{
Fernando Antonio Lucena Aiube \\ Winicius Botelho Faquieri
}

\begin{abstract}
In this paper we analyze the ability of different asset classes to hedge the Brazilian stock index in periods of high and low interest rates in the Brazilian economy, using two multivariate GARCH models. Our analysis includes two categories of assets: those traded in domestic currency and those traded in U.S. dollars. From the perspective of a local investor, we find that the exchange rate (R $\$$ US\$) and gold are the assets least correlated with equities. From the standpoint of a foreign investor, commodity index and fixed-income assets are the most useful. These results prevail in the low- and high-interest-rate periods. Moreover, in the period of low interest rates, the standard deviation of the estimated conditional correlation time series decreases, suggesting that in this period investors are more confident about macroeconomic policies.
\end{abstract}

Keywords: Hedging equities; MGARCH models; Brazilian stock market. JEL Code: C22, C54, C58.

\section{Introduction}

At the end of 2019, the interest rate in Brazil reached its lowest level in more than 20 years. This was a consequence of a prior period of recession and a recent economic environment of low inflation. The creation of the Real Plan in 1994 allowed the Brazilian economy to achieve macroeconomic stabilization. In the same direction, institutional reforms adopted in the ensuing years reinforced macro and fiscal policies (floating exchange rate, inflation targeting system and primary surplus target), keeping inflation low (Afonso et al.; 2016).

The Brazilian Central Bank (BCB) found sufficient conditions to start cutting the interest rate in 2016 as a response to economic stagnation. On the other hand, the nominal interest rates in central economies at that time had been low since 2009 , a situation that has continued. Indeed, both short- and long-term rates have been persistently low in recent years. In Japan and the

Submitted on May 27, 2020. Revised on August 2nd, 2020. Accepted on August 6, 2020. Published online in September 2020. Editor in charge: Marcelo Fernandes.

${ }^{\dagger}$ Faculty of Economic Sciences - UERJ and Graduate Program in Administration - UFF, Brazil: faiube@gmail.com

${ }^{\ddagger}$ Faculty of Economic Sciences - UERJ, Brazil: wfaquieri@gmail.com 
Euro Zone many government bonds have been traded at negative yields for several years; see Borio and Hofmann (2017).

From the investment perspective, this big movement in the Brazilian market prompted many agents to look for better returns in equity markets. Hence, the B3 (Brazilian Stock Exchange in São Paulo) received a huge volume of funds and the number of investors more than doubled in the last two years (see the B3 report). The economic rationale behind this fact is that in a lowinterest-rate regime, firms' cash flows are discounted with lower cost of capital, so they naturally become more valuable.

Because of the greater risks of equity markets, investors need more efficient risk control measures for their allocations. This can come from using diversification strategies or derivative instruments. In both cases, investors aim to reduce their exposure. The diversification strategy is related to the correlation between assets. In this paper, we examine the conditional correlations of the Brazilian equity market considering a portfolio with different asset classes in the period of low interest rates. We compare these results with the previous period of high interest rates. We also analyze a broad period encompassing low and high interest rates. We consider potential assets for hedging from two different perspectives. First, we use only locally-traded (domestic) assets (the stock index, exchange rate, a local commodity index, a local fixed-income asset, a cryptocurrency, and gold). Second, we consider a foreign agent investing in Brazilian equities traded in U.S. dollars. We examine the potential use of foreign assets (the domestic stock index, a commodity index, a fixed income asset, a cryptocurrency, and gold, all traded in U.S. dollars). We estimate the conditional correlation among these assets in each case. To this end, we use multivariate generalized autoregressive conditional heteroskedastic (MGARCH) models.

The main goal is to distinguish from among different asset classes those that are more appropriate for hedging/diversification purposes. Sadorsky (2014) and Manera et al. (2013) use the same method, although with different objectives. The motivation of this type of analysis is the fact that markets quickly react to changes in interest rate dynamics.

The paper contributes to the analysis of hedging possibilities in a lowinterest regime of an emerging economy using domestic and foreign assets. This study has clear implications for investors, portfolio managers and practitioners facing new challenges for asset allocation in a new environment of low interest rates that seemingly will prevail for a long time.

The paper is organized as follows: Section 2 presents an overview of the literature; Section 3 details the models used; Section 4 exhibits the data; Section 5 discusses the results; and Section 6 concludes. 


\section{Literature overview}

The literature on portfolio allocation is fundamentally based on the assessment of the correlation coefficient among the assets composing a portfolio. The terms "hedging" and "diversification" are important topics in the financial literature. Efforts to study these issues evolved notably in the mid1990s and 2000s, when many conditional correlation models were developed. Engle and Kroner (1995) explore the specification of Baba et al. (1990), calling it the BEKK representation. Tse and Tsui (2002) propose a multivariate autoregressive conditional heteroskedastic model with time-varying correlations, belonging to the class of dynamic conditional correlation (DCC) models. They adopt the conditional variance formulation of GARCH models where the conditional correlation is considered an autoregressive moving average. In this direction, Engle (2002) proposes a simpler DCC model, compared to the previous ones. The author joins the univariate variance models of the GARCH family with a more parsimonious correlation specification, where the conditional correlation is specified as a weighted sum of past correlations. Another convenience of this formulation is that the parameters of the variance and correlation equations can be estimated separately in two steps. We call the Engle (2002) model DCC-GARCH from now on. McAleer et al. (2008) propose a generalized autoregressive conditional correlation model (VARMA-AGARCH). Unlike the formulations of Engle (2002) and Tse and Tsui (2002), this model imposes no restrictions on the parameters of the conditional correlation.

There is a vast literature on the applications of these models. In general, these applications aim to investigate the correlation among different asset classes and the implication for portfolio allocation. Many authors examine the ability of commodity and cryptocurrencies to diversify/hedge equity positions. Sadorsky (2014) examines the correlations between emerging-market stock prices and the prices of copper, oil, and wheat. He compares the models of McAleer et al. (2008) (VARMA-AGARCH) and the DCC of Engle (2002) (DCC-GARCH). He concludes that the DCC-GARCH fits the data better and that oil provides the cheapest hedge for emerging-market stock prices. Creti et al. (2013) use the DCC-GARCH method to investigate the links between commodities and stocks in the period from January 2001 to November 2011. Their main conclusion relates to gold's behavior, which exhibited a negative correlation with stocks most of the time. Manera et al. (2013) analyze energy and agricultural commodities, examining whether macroeconomic factors affect these commodity sectors. They find that the S\&P 500 index and exchange rate significantly affect returns. Chang et al. (2013) investigate the condi- 
tional correlations and spillovers between crude oil (six different types) and financial markets (four equity indexes). They use different conditional correlation models and compare the results. They find that the VARMA-AGARCH model provides little evidence of volatility spillovers between crude oil and financial markets. The results of DCC-GARCH are always significant. Olson et al. (2017) investigate whether commodities are effective hedges for equity investors. They use different methods to estimate hedge ratios: realized variance and covariance, the BEKK model of Engle and Kroner (1995), and recursive OLS regressions. They find evidence that commodities were not good hedges for the S\&P 500 in the period analyzed. Klein et al. (2018) study the behavior of Bitcoin, gold, and silver in a portfolio of equity indexes and WTI (West Texas Intermediate) crude oil. They find that Bitcoin does not present stable hedging performance and is correlated positively with downward markets. Moreover, they find that gold and Bitcoin have fundamentally different properties related to equity markets.

Applications of MGARCH models to the Brazilian market are also extensive. Ferreira and De Mattos (2014) use the BEKK model to investigate the contagion effect of the subprime crises on the Brazilian stock market. Using a sample of indexes from 2007 to 2010, they find evidence of contagion between U.S. and Brazilian stock indexes. Marçal and Valls Pereira (2009) examine signals of contagion during the 1990s coming from many financial crises in that decade. They investigate the behavior of bond markets in different countries using MGARCH models and find evidence supporting the contagion hypothesis. Vartanian (2020) analyzes the linkage between commodity prices (Commodity Research Bureau index) and the Brazilian stock market index (Ibovespa) through the BEKK model. Although Ibovespa is a diversified index, it contains many stocks of commodity-producing firms (e.g. Vale and Petrobras). He finds that the conditional correlation is relatively small and that the commodity index is useful for risk diversification of equities, proxied by the Brazilian stock index.

In this paper we investigate the conditional correlation among Brazilian equity prices, focusing on the most popular MGARCH models: the BEKK of Engle and Kroner (1995) and DCC-GARCH of Engle (2002).

\section{The model setup}

We describe the dynamic correlation between the Brazilian equity index and different asset classes using the BEKK and DCC-GARCH models. Consider $\boldsymbol{y}_{t}$ the vector of log-returns of $n$ assets. The mean equation is written as 


$$
\begin{aligned}
\Phi(L) \boldsymbol{y}_{t} & =\boldsymbol{\mu}+\Theta(L) \boldsymbol{\varepsilon}_{t} \quad t=1, \ldots, T \\
\boldsymbol{\varepsilon}_{t} & =\boldsymbol{z}_{t} \boldsymbol{H}_{t}^{\frac{1}{2}}
\end{aligned}
$$

where $L$ is the lag operator of the AR and MA polynomials $\Phi(L)=1-$ $\phi_{1} L-\ldots-\phi_{r} L^{r}$ and $\Theta(L)=1+\theta_{1} L+\ldots+\theta_{s} L^{s}$, respectively. $z_{t}$ is an $n-$ dimensional iid process with mean zero and covariance identity matrix $\boldsymbol{I}_{n}$. In this formulation one can write $E\left[\boldsymbol{\varepsilon}_{t} \mid \mathscr{F}_{t-1}\right]=0$ and $E\left[\boldsymbol{\varepsilon}_{t} \boldsymbol{\varepsilon}_{t}^{\top} \mid \mathscr{F}_{t-1}\right]=\boldsymbol{H}_{t}$, where $\mathscr{F}_{t}$ is the information set available at time $t$ and $\boldsymbol{H}_{t}$ is the conditional covariance matrix. There are different forms of the specification of matrix $\boldsymbol{H}_{t}$. For each formulation we have a different MGARCH model. In this paper we use two specifications. In both cases we consider a MGARCH $(1,1)$ model.

Consider the formulation given by

$$
\boldsymbol{H}_{t}=\boldsymbol{C}^{\top} \boldsymbol{C}+\boldsymbol{A}^{\top} \boldsymbol{\varepsilon}_{t-1} \boldsymbol{\varepsilon}_{t-1}^{\top} \boldsymbol{A}+\boldsymbol{B}^{\top} \boldsymbol{H}_{t-1} \boldsymbol{B},
$$

where $\boldsymbol{C}, \boldsymbol{A}$ and $\boldsymbol{B}$ are $n \times n$ matrices and $\boldsymbol{C}$ is symmetric and positive definite. Engle and Kroner (1995) call equation (2) the BEKK representation based on Baba et al. (1990). More specifically, equation (2) is the $\operatorname{BEKK}(1,1)$ model; a more general BEKK $(\mathrm{p}, \mathrm{q})$ is presented in the appendix. Since the second and third terms of the right-hand-side of equation (2) are expressed in quadratic form, $\boldsymbol{H}_{t}$ is positive definite without any constraints on $\boldsymbol{A}$ and $\boldsymbol{B}$. In the case where $\boldsymbol{C}=\left\{c_{i, j}, i \geq j\right\}$, the number of parameters in the $\operatorname{BEKK}(1,1)$ model is $n(5 n+1) / 2$, which becomes very large as $n$ increases. To reduce the number of parameters, one can choose $\boldsymbol{A}$ and $\boldsymbol{B}$ to be diagonal matrices, that is $\boldsymbol{A}=\left\{a_{i j}\right\}$, where $a_{i, j}=0$ if $i \neq j$ and $\boldsymbol{B}=\left\{b_{i, j}\right\}$, where $b_{i, j}=0$ if $i \neq j$. In this case, equation (2) is called the diagonal BEKK $(1,1)$ model, which is the first representation used in this article. The model is estimated using the QMLE (quasi maximum likelihood estimator); see Gouriéroux (2012) for a detailed discussion of the QMLE method.

The second representation is the DCC of Engle (2002), which is called the DCC-GARCH model. This model is estimated in two steps. In the first step, the GARCH parameters are estimated using a univariate GARCH model. In this study we use the following univariate GARCH models: (i) GARCH (p,q) model of Bollerslev (1986); (ii) GJR (p,q) model of Glosten et al. (1993); and (iii) EGARCH (p,q) model of Nelson (1991). The variance equations of these models are presented in the appendix. In the second step, the time-varying conditional correlation matrix $\boldsymbol{R}_{t}$ is estimated considering

$$
\boldsymbol{H}_{t}=\boldsymbol{D}_{t} \boldsymbol{R}_{t} \boldsymbol{D}_{t},
$$


where $\boldsymbol{R}_{t}$ must be invertible and positive definite, and where $\boldsymbol{D}_{t}$ is a diagonal matrix composed of $h_{i j}$ obtained in the first step of the estimation procedure, namely, $\boldsymbol{D}_{t}=\operatorname{diag}\left(\sqrt{h_{11} t}, \ldots, \sqrt{h_{n n t}}\right)$. To guarantee that $\boldsymbol{R}_{t}$ is positive definite an approximation matrix $\boldsymbol{Q}_{t}$ is used, given by

$$
\boldsymbol{Q}_{t}=(1-a-b) \overline{\boldsymbol{Q}}+a \boldsymbol{z}_{t-1} \boldsymbol{z}_{t-1}^{\top}+b \boldsymbol{Q}_{t-1},
$$

where $a$ and $b$ are non-negative and $a+b<1$ to ensure stationarity. $\bar{Q}$ is the unconditional matrix of standardized errors $\boldsymbol{z}_{t}$. The conditional correlation matrix $\boldsymbol{R}_{t}$ is given by

$$
\boldsymbol{R}_{t}=\operatorname{diag}\left(\boldsymbol{Q}_{t}\right)^{-1 / 2} \boldsymbol{Q}_{t} \operatorname{diag}\left(\boldsymbol{Q}_{t}\right)^{-1 / 2} .
$$

The estimation procedure follows the two-step estimation technique and the QMLE; see Engle (2002).

\section{The data}

To investigate the hedging/diversification features of Brazilian stocks, we choose different asset classes based on the following reasons. The usefulness of Bitcoin as a hedging asset has been investigated recently in the literature and the results are controversial. Klein et al. (2018) find no stable hedging capabilities for Bitcoin. Bouri et al. (2017) find that Bitcoin is a poor hedge for stock indexes but suitable for diversification purposes and that these properties vary according the horizon. Dyhrberg (2016) concludes that Bitcoin can be used to hedge stocks. It is well-known that gold is a safe haven. For example, Baur and Lucey (2010) find that gold is a hedge against stocks and a safe haven during market distress. The literature on commodities analyzing their properties as an asset class appropriate for diversification of equity positions is extensive. On this topic, we mention Gorton and Rouwenhorst (2006) and Erb and Harvey (2006). Lombardi and Ravazzolo (2016) claim that the usefulness of commodities as hedging instruments is not guaranteed. The financialization phenomenon of commodities modified their main features as a diversification asset, making them more volatile and also more correlated with equities. A survey of this topic is found in Cheng and Xiong (2014). Fixed-income assets are interesting to decrease the volatility of portfolios, making them less risky. Historically, from the perspective of Brazilian investors, the exchange rate has been a useful asset to escape the turmoil of undesirable macroeconomic policies and political events.

The data comprise two portfolios containing assets that can potentially be used to hedge/diversify equity exposure. They have different information. The first portfolio comprises assets traded in local currency (reais, R\$), and 
the second, assets traded in U.S. dollars. The first portfolio includes the following series traded in R\$: (i) BOVA11 is the exchange traded fund (ETF) used as a proxy for the Brazilian stock index, Ibovespa; (ii) gold traded in $\mathrm{R} \$$ /gram; (iii) exchange rate in R $\$ / U S \$$; (iv) a fixed-income asset, represented by the NTN-B (National Treasury Notes) with maturity on 05/15/2045, a nonpaying coupon bond; (v) Bitcoin, traded in R\$; and (vi) an index of commodities traded on the B3 as a broad measure of the Brazilian commodity markets, composed of sugar, cattle, coffee, corn, soybean, ethanol, gold, and oil.

In the second portfolio we consider all asset prices denominated in U.S. dollars. It is composed of the following series: (i) EWZ, an ETF traded on the NYSE (New York Stock Exchange), which tracks the Brazilian equity index; (ii) Bitcoin; (iii) gold, in the form of a first future contract of gold prices; (iv) U.S. 10-year T-bond yield; and (v) GSCI, the S\&P-GSCI (formerly known as the Goldman Sachs Commodities Index), created in 1991 and currently owned by Standard and Poor's. It includes the following commodity sectors: energy, industrial metals, agriculture, livestock, and precious metals.

The sample for all series encompasses the period from 01/17/2014 to $12 / 30 / 2019$ and is based on daily closing prices. Bitcoin is traded on all days of the year, so we use only the market trading day prices. All data were obtained from the Bloomberg platform except the NTN-B series, which was obtained from the Brazilian Fixed-Income website, ${ }^{1}$ and Bitcoin traded in R \$, obtained from the Brazilian exchange Mercado Bitcoin.

For each series, we compute the continuous compounded returns as the difference $\log \left(P_{t}\right)-\log \left(P_{t-1}\right)$, where $P_{t}$ is the daily closing price. Table 1 describes the main statistics of the first portfolio for the entire period sampled. Each series contains 1,456 observations.

We note that Bitcoin is the most volatile among all assets. The excess of kurtosis indicates the presence of fat tails in the log-returns of all empirical distributions. The Ljung-Box test for squared returns rejects the null hypothesis of no correlation up to lag 10. The ARCH-LM test rejects the null hypothesis of no heteroskedasticity (except for the NTN-B at 5\% significance level).

Table 2 describes the main statistics of the second portfolio, denominated in U.S. dollars. Again, Bitcoin is the most volatile asset. All assets present fat tails and heteroskedasticicty.

Table 3 exhibits the unconditional correlation among assets in the portfolio denominated in local currency. The highest correlation is between the exchange rate and gold. The connection between these assets is related to the no-arbitrage condition between gold traded in local currency and gold traded

${ }^{1}$ See https://sisweb.tesouro.gov.br/apex/f?p=2031:2:0: : : : 
Table 1

Main statistics: Asset returns in local currency

\begin{tabular}{lcccccc}
\hline & BOVA11 & gold & USDBRL & NTN-B & \multicolumn{1}{c}{ BTC } & GSCI \\
\hline mean (annualized) & 0.1454 & 0.1327 & 0.0936 & 0.1304 & 0.4731 & 0.1321 \\
std dev (annualized) & 0.2311 & 0.1957 & 0.1633 & 0.1642 & 0.7480 & 0.1145 \\
max & 0.0678 & 0.0834 & 0.0727 & 0.0871 & 0.3006 & 0.0334 \\
min & -0.0906 & -0.0466 & -0.0560 & -0.1351 & -0.2644 & -0.0267 \\
skewness & -0.0544 & 0.2754 & 0.1535 & -1.0477 & 0.1205 & 0.2032 \\
kurtosis & 1.9076 & 3.1999 & 3.1138 & 27.4791 & 4.9284 & 0.8474 \\
$Q(10)$ & 8.3451 & 26.8075 & 19.3981 & 32.7696 & 9.6138 & 10.9143 \\
& $(0.5952)$ & $(0.0027)$ & $(0.0354)$ & $(0.0003)$ & $(0.4750)$ & $(0.3642)$ \\
$Q^{2}(10)$ & 82.8133 & 77.5996 & 80.4011 & 20.3029 & 104.6683 & 52.9338 \\
& $(0.00)$ & $(0.00)$ & $(0.00)$ & $(0.0265)$ & $(0.00)$ & $(0.00)$ \\
ARCH(10) & 54.2264 & 55.0908 & 59.9782 & 17.4790 & 71.8819 & 43.3700 \\
& $(0.00)$ & $(0.00)$ & $(0.00)$ & $(0.0644)$ & $(0.00)$ & $(0.00)$ \\
\hline
\end{tabular}

Notes: Kurtosis means the excess of kurtosis; $Q(10)$ and $Q^{2}(10)$ denote Ljung-Box statistics with 10 lags for returns and squared returns, respectively; and ARCH (10) is the ARCH-LM test with 10 lags. The p-values are in parentheses.

Table 2

Main statistics: Asset returns in U.S. dollars

\begin{tabular}{lccccc}
\hline & EWZ & gold & GSCI & BTC & bond \\
\hline mean (annualized) & 0.0420 & 0.0359 & -0.0584 & 0.3733 & -0.0768 \\
std dev (annualized) & 0.3341 & 0.1304 & 0.1932 & 0.7305 & 0.3142 \\
max & 0.0848 & 0.0456 & 0.07600 & 0.5551 & 0.1069 \\
min & -0.1784 & -0.0356 & -0.0506 & -0.2387 & -0.0965 \\
skewness & -0.4716 & 0.2470 & 0.0273 & -0.1637 & 0.1075 \\
kurtosis & 3.9845 & 2.5791 & 2.3277 & 4.8617 & 1.8694 \\
$Q(10)$ & 9.3791 & 20.2414 & 12.2792 & 16.0407 & 32.5796 \\
& $(0.4965)$ & $(0.0271)$ & $(0.2668)$ & $(0.0985)$ & $(0.0003)$ \\
$Q^{2}(10)$ & 45.2319 & 22.9131 & 148.7232 & 133.9348 & 163.1855 \\
& $(0.00)$ & $(0.0111)$ & $(0.00)$ & $(0.000)$ & $(0.00)$ \\
ARCH (10) & 33.5640 & 22.3432 & 86.3451 & 85.6207 & 89.8263 \\
& $(0.0002)$ & $(0.0134)$ & $(0.00)$ & $(0.000)$ & $(0.00)$ \\
\hline
\end{tabular}

Notes: Kurtosis means the excess of kurtosis; $Q(10)$ and $Q^{2}(10)$ denote Ljung-Box statistics with 10 lags for returns and squared returns, respectively; and $\mathrm{ARCH}(10)$ is the ARCH-LM test with 10 lags. The p-values are in parentheses.

in U.S. dollars. This means that any change in the exchange rate is translated to gold prices traded in local currency. Note also the high correlation between Bitcoin traded in reais and the exchange rate. This is also expected according to no-arbitrage condition between Bitcoin traded in local currency and that traded in U.S. dollars. The lowest correlation observed is between BOVA11 and the exchange rate. BOVA11 is unconditionally negatively correlated with all assets except the NTN-B. Table 4 presents the unconditional correlation among assets denominated in U.S. dollars. The EWZ has the lowest unconditional correlation with Bitcoin and the highest with the GSCI, followed by 
Table 3

Unconditional correlations: Assets in local currency

\begin{tabular}{lcccccc}
\hline & BOVA11 & BTC & GSCI & USDBRL & gold & NTN-B \\
\hline BOVA11 & 1 & & & & & \\
BTC & -0.075 & 1 & & & & \\
GSCI & -0.094 & 0.071 & 1 & & & \\
USDBRL & -0.486 & 0.224 & 0.194 & 1 & & \\
gold & -0.338 & 0.138 & 0.251 & 0.510 & 1 & \\
NTN-B & 0.194 & -0.049 & -0.183 & -0.151 & -0.166 & 1 \\
\hline
\end{tabular}

Table 4

Unconditional correlations: Assets traded in U.S. dollars

\begin{tabular}{lccccc}
\hline & EWZ & BTC & GSCI & gold & bond \\
\hline BOVA11 & 1 & & & & \\
BTC & 0.007 & 1 & & & \\
GSCI & 0.356 & 0.005 & 1 & & \\
gold & 0.030 & 0.028 & 0.067 & 1 & \\
bond & 0.132 & 0.019 & 0.228 & -0.394 & 1 \\
\hline
\end{tabular}

the fixed-income asset.

\section{Results}

We proceed with the estimation of both models. The order $(\mathrm{p}, \mathrm{q})$ was chosen based on the AIC (Akaike information criterion) of Akaike (1974) and on the BIC (Bayesian information criterion) of Schwarz (1978). To consider even more parsimonious models, we adopt for the mean equation (1a), an $\mathrm{AR}(1)$ specification when it filters out the autogressive dependence at 5\% significance level in the Ljung-Box statistics. During the estimation procedure we noted, based on the AIC/BIC criteria, that the best fit was obtained when the asymmetric effect of shocks was considered in the variance equation with symmetric distributions. Among all symmetric distributions, the Student distribution fit the data best. The degrees of freedom were estimated jointly with all parameters involved.

To save space we present the main estimation issues for the period from 01/17/2014 to 12/30/2019 in local currency. All other estimation results are available upon request. Table 5 exhibits the univariate models that were selected in the first estimation step of the DCC-GARCH $(1,1)$ model.

Table 6 presents the parameters of equation 4 and for the distribution $z_{t} \sim t_{v}\left(\mathbf{0}, \boldsymbol{I}_{6}\right)$ that were obtained for the DCC-GARCH $(1,1)$ estimation in the second step. 


\section{Table 5}

DCC-GARCH model

estimation: First step

\begin{tabular}{lcc}
\hline \multirow{2}{*}{ asset } & \multicolumn{2}{c}{ model } \\
\cline { 2 - 3 } & mean & variance \\
\hline BOVA11 & ARMA $(0,0)$ & EGARCH $(1,1)$ \\
BTC & ARMA $(1,0)$ & GJR $(1,1)$ \\
GSCI & ARMA $(1,0)$ & GJR $(1,1)$ \\
USDBRL & ARMA $(1,0)$ & EGARCH $(2,1)$ \\
gold & ARMA $(0,2)$ & EGARCH $(1,1)$ \\
NTN-B & ARMA $(1,0)$ & EGARCH $(1,1)$ \\
\hline
\end{tabular}

Table 6

DCC-GARCH model

estimation: Second step

\begin{tabular}{lll}
\hline parameter & estimate & p-value \\
\hline $\mathrm{a}$ & 0.012738 & $(0.0001)$ \\
$\mathrm{b}$ & 0.948307 & $(0.0000)$ \\
$v$ & 9.141428 & $(0.0000)$ \\
\hline
\end{tabular}

For the diagonal BEKK $(1,1)$ model, Tables 7 and 8 present the estimation results for the mean and variance equations, respectively.

Table 7

Diagonal BEKK model estimation:

Mean equation

\begin{tabular}{lrr}
\hline \multirow{2}{*}{ asset } & \multicolumn{2}{c}{ parameters } \\
\cline { 2 - 3 } & \multicolumn{1}{c}{$\mu$} & \multicolumn{1}{c}{$\phi_{1}$} \\
\hline BOVA11 & $0.000923(0.0071)$ & $-0.077855(0.0011)$ \\
BTC & $0.001382(0.1307)$ & $0.031094(0.2093)$ \\
GSCI & $0.000309(0.0763)$ & $0.004987(0.8236)$ \\
USDBRL & $0.000343(0.1332)$ & $-0.187373(0.0000)$ \\
gold & $0.000455(0.0809)$ & $-0.125518(0.0000)$ \\
NTN-B & $0.000825(0.0000)$ & $-0.099726(0.0000)$ \\
\hline \hline distribution & \multicolumn{2}{c}{ parameter $(v)$} \\
\hline$z_{t} \sim t_{v}\left(0, I_{6}\right)$ & \multicolumn{2}{c}{$7.4838(0.0000)$} \\
\hline Note:
\end{tabular}

Note: p-values in parentheses.

\subsection{Analysis in local currency}

Here we analyze the conditional correlation between the Brazilian equity index in the first portfolio (all assets traded in local currency). In this analy- 


\section{Table 8}

Diagonal BEKK model estimation: Variance equation

\begin{tabular}{rll}
\hline$C=\left\{c_{i j}, i \geq j\right\}$ & $A=\left\{a_{i j}, i=j\right\}$ & $B=\left\{a_{i j}, i=j\right\}$ \\
\hline $3.35 \times 10^{-6}(0.0402)$ & $0.103493(0.00)$ & $0.986959(0.00)$ \\
$-3.17 \times 10^{-6}(0.0155)$ & $0.318079(0.00)$ & $0.935703(0.00)$ \\
$-4.25 \times 10^{-7}(0.1007)$ & $0.144323(0.00)$ & $0.940022(0.00)$ \\
$-8.56 \times 10^{-7}(0.0052)$ & $0.132635(0.00)$ & $0.987423(0.00)$ \\
$-5.29 \times 10^{-7}(0.0238)$ & $0.141631(0.00)$ & $0.986217(0.00)$ \\
$8.54 \times 10^{-7}(0.0043)$ & $0.219778(0.00)$ & $0.940343(0.00)$ \\
$5.33 \times 10^{-5}(0.0000)$ & & \\
$1.52 \times 10^{-6}(0.1378)$ & & \\
$4.20 \times 10^{-6}(0.0000)$ & & \\
$1.98 \times 10^{-6}(0.0477)$ & & \\
$-4.67 \times 10^{-7}(0.6843)$ & & \\
$5.42 \times 10^{-6}(0.0021)$ & & \\
$9.19 \times 10^{-7}(0.0038)$ & & \\
$1.22 \times 10^{-6}(0.0040)$ & & \\
$-7.37 \times 10^{-7}(0.0055)$ & & \\
$8.50 \times 10^{-7}(0.0049)$ & & \\
$3.53 \times 10^{-7}(0.0069)$ & & \\
$-6.74 \times 10^{-7}(0.0011)$ & & \\
$1.12 \times 10^{-6}(0.0059)$ & & \\
$-5.54 \times 10^{-7}(0.0183)$ & & \\
$4.95 \times 10^{-6}(0.0000)$ & & \\
\hline
\end{tabular}

Note: p-values in parentheses.

sis, we run the BEKK and DCC-GARCH models considering the period from $08 / 01 / 2017$ to $12 / 30 / 2019$. This is a subsample of the entire sample described in Section 4. The Brazilian Central Bank started cutting the interest rate from $14 \%$ a year in the middle of 2016. In this subsample, the prevailing interest rate was less than $10 \%$ a year (with sample size of 596 observations). This movement was in accordance with prior monetary policy adopted by the Federal Reserve and the European Central Bank (ECB), applied in the USA and Euro Zone, respectively. From the investor's perspective, this was an incentive to shift investments to equities. Actually, this made the stock index climb to historically high levels by the end of 2019 , when the benchmark interest rate was $4.5 \%$ a year.

In the second analysis, we run both models considering the period from $01 / 17 / 2014$ to $12 / 29 / 2016$, during which the interest rate was above $10 \%$ a year (with sample size of 720 observations). In the third analysis, we run both models considering the whole sample from $01 / 17 / 2014$ to $12 / 30 / 2019$,

\footnotetext{
${ }^{2}$ Although the interest rate of $10 \%$ a year is not low compared with central economies, from the Brazilian perspective one digit was a remarkable situation. That is why here we call it a low interest rate.
} 
Table 9

Low-interest-rate period (08/01/2017 - 12/30/2019): Statistics based on conditional correlations

\begin{tabular}{llrrrrr}
\hline \multirow{2}{*}{ DCC-GARCH } & \multicolumn{1}{c}{ gold } & USDBRL & NTN-B & BTC & GSCI \\
\cline { 2 - 7 } & mean & -0.2478 & -0.5287 & 0.2058 & -0.0513 & -0.1182 \\
& std. dev & 0.0175 & 0.0151 & 0.0188 & 0.0184 & 0.0206 \\
& min & -0.3530 & -0.5787 & 0.1240 & -0.1421 & -0.2138 \\
& max & -0.2066 & -0.4843 & 0.2773 & 0.0027 & -0.0586 \\
\cline { 2 - 7 } BEKK & mean & -0.2460 & -0.5178 & 0.2236 & -0.0784 & -0.1174 \\
& std. dev & 0.0331 & 0.0182 & 0.0225 & 0.0282 & 0.0165 \\
& min & -0.3694 & -0.5415 & 0.0940 & -0.1553 & -0.1561 \\
& max & -0.1313 & -0.4469 & 0.2679 & -0.0144 & -0.0015 \\
\hline
\end{tabular}

also including the transition period from high to low interest rates.

Table 9 presents the main statistics of the conditional correlation series in the first analysis covering the period from 08/01/2017 to 12/30/2019.

The exchange rate and gold present the highest correlations in absolute value with the equity index. Hence they are the most appropriate among all assets examined to hedge the equity index. Being negatively correlated, a long (short) position in the equity index should be hedged with a long (short) position in the exchange rate and/or gold. The local fixed-income asset has positive correlations with equity index throughout the period. Hence, a long (short) position in equity index should be hedged by shorting (buying) the fixed-income asset. The BEKK and DCC-GARCH models give the same response regarding the order from the most- to least-useful hedging asset. In the DCC-GARCH model, the exchange rate has the lowest standard deviation. This is a desirable property for those looking for an asset to hedge positions. In the BEKK model, the exchange rate and gold present the highest mean correlations in absolute value among all assets. In this case, the strategy would be the same. From both models, one observes that diversification would be more appropriate with Bitcoin. Moreover, the results of both models are very similar.

Table 10 exhibits the main statistics of the conditional correlation series for the second analysis, covering the period from 01/17/2014 to 12/29/2016. Higher interest rates prevail in this period, compared to the previous one.

In both models, the exchange rate is again the best asset to hedge, followed by gold. Both assets have the highest correlations in absolute value with the market index. Long (short) positions in these assets hedge a long (short) position in the equity index. According to the DCC-GARCH model, the exchange rate presents the lowest standard deviation. However, in the BEKK model, gold and the exchange rate have the highest standard devi- 
Table 10

High-interest-rate period (01/17/2014 to 12/29/2016): Statistics based on conditional correlations

\begin{tabular}{llrrrrr}
\hline \multirow{3}{*}{ DCC-GARCH } & \multicolumn{1}{c}{ gold } & USDBRL & NTN-B & BTC & GSCI \\
\cline { 2 - 7 } & mean & -0.3625 & -0.4452 & 0.1357 & -0.1283 & -0.0752 \\
& std. dev & 0.0311 & 0.0276 & 0.0289 & 0.0326 & 0.0340 \\
& min & -0.4552 & -0.5389 & 0.0824 & -0.2379 & -0.1676 \\
BEKK & max & -0.2835 & -0.3394 & 0.2729 & 0.0526 & 0.0355 \\
\cline { 2 - 7 } & mean & -0.3515 & -0.4415 & 0.0929 & -0.1399 & -0.0567 \\
& std. dev & 0.0558 & 0.0552 & 0.0272 & 0.0422 & 0.0074 \\
& min & -0.5460 & -0.5721 & 0.0351 & -0.2114 & -0.1910 \\
& max & -0.2585 & -0.3102 & 0.2497 & 0.1218 & -0.0374 \\
\hline
\end{tabular}

Table 11

Entire sample period (01/17/2014 - 12/30/2019): Statistics based on conditional correlations

\begin{tabular}{llrrrrr}
\hline & & gold & USDBRL & NTN-B & BTC & GSCI \\
\cline { 2 - 7 } DCC-GARCH & mean & -0.3200 & -0.4983 & 0.2057 & -0.0976 & -0.0923 \\
& std. dev & 0.0517 & 0.0426 & 0.0534 & 0.0434 & 0.0511 \\
& min & -0.6080 & -0.7322 & 0.0743 & -0.2332 & -0.3429 \\
& max & -0.2134 & -0.3730 & 0.5795 & 0.0689 & 0.0711 \\
\cline { 2 - 7 } BEKK & mean & -0.2982 & -0.4783 & 0.1569 & -0.1079 & -0.0750 \\
& std. dev & 0.0842 & 0.0689 & 0.0703 & 0.0918 & 0.0520 \\
& min & -0.5656 & -0.7100 & -0.0414 & -0.4158 & -0.3343 \\
& max & -0.1268 & -0.2777 & 0.5651 & 0.1819 & 0.0952 \\
\hline
\end{tabular}

ations. DCC-GARCH and BEKK give mixed results regarding the fixedincome asset and Bitcoin. The commodity index is the best asset for the diversification strategy.

Comparing the periods of low and high interest rates, we note that the magnitude of the mean correlations does not change significantly. The exchange rate and gold are robust assets to hedge equities in local currency, no matter how low the interest rate is. However, Bitcoin and the commodity index interchanged positions in the two periods. Note also, from both models, that the standard deviation is greater in the period of high interest rates (except for the commodity index). In other words, the changes around the mean were narrower during the period of lower interest rates. This result can be interpreted as reflecting the greater confidence of investors in the allocation during the period when the interest rate was falling. This means agents were more comfortable with the direction of monetary policy.

Table 11 presents the results for the whole period sampled, including moments of high and low interest rates. In both models, the exchange rate 
Figure 1

Conditional correlations in local currency for the DCC-GARCH model from $01 / 17 / 2014$ to $12 / 30 / 2019$

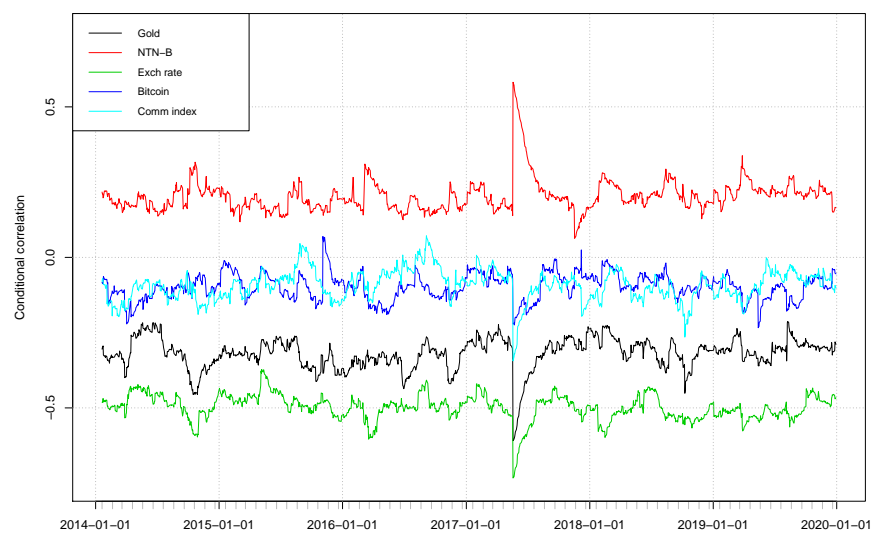

presents the highest mean correlation in absolute value with the equity index, followed by gold. Moreover, the exchange rate has the lowest standard deviation measured by the DCC-GARCH model and the second-lowest based on the BEKK model. The NTN-B is the third most useful asset among those analyzed, and the conditional correlations are all positive for the whole sample, as can be seen from the DCC-GARCH. Shorting the NTN-B would provide hedge of long-equity-index positions. On the other hand, the exchange rate and gold have negative conditional correlations with BOVA11 during the entire period analyzed. The commodity index presented the lowest mean conditional correlation in absolute value and would be the most useful asset for diversification. We repeated the analysis considering a different Treasury note, maturing on 05/15/2050, and the results were similar. To save space, we do not present the estimation results for both previous periods. They are available upon request.

Figure 1 shows the conditional correlation time series between BOVA11 and all other assets obtained from the DCC-GARCH model. We observe that recent Brazilian political events affected these correlation series. At the end of 2014, an upward movement of the exchange rate and gold and a downward movement of equities were responses to the reelection of leftist Dilma Rousseff as president. One can also observe a strong movement on 05/18/2017. On this day, the circuit breaker interrupted trading on the B3 when the Ibovespa 
index plunged more than $12 \%$. This episode was named Joesley Day. ${ }^{3}$ This movement in prices disrupted all correlations instantaneously. Also on this day, the NTN-B (the fixed-income asset) plunged together with the equity index. It followed a symmetric direction compared to all other assets. However, this movement is consistent with its positive correlation with the equity index. Subsequently, there was a transition period to normal evolution of the correlation series. In general, a strong shock makes equity investors quickly change their allocations. This disruption is consistent with similar studies encompassing the subprime crisis period. For example, Sadorsky (2014) and Lombardi and Ravazzolo (2016), using the DCC-GARCH, find this type of break in September 2008. At this same moment, Vartanian (2020), analyzing the Brazilian market, verifies the same fact using the BEKK model.

\subsection{Analysis in U.S. dollars}

Results of the analysis of the most recent period, from 08/01/2017 to 12/30/2019, when low interest rates prevailed, are presented in Table 12. According to the DCC-GARCH model, the best strategy for investors with long (short) positions in EWZ would be to short (buy) the GSCI. The second-best option would be the fixed-income asset. Both assets presented positive mean conditional correlation during whole period. Moreover, the GSCI exhibited the lowest standard deviation among all of them. Results of the BEKK model present the same order of preference for such investors. From both models, Bitcoin is the most useful asset for diversification.

The results for the period of high interest rates, from 01/17/2014 to 12/29/2016, are presented in Table 13. According to the DCC-GARCH model, the best strategy to hedge a long (short) position in EWZ would be to short (buy) the GSCI. The second-best strategy would be to short (buy) the fixed-income asset. The BEKK model gives the same order of preference. Both models indicate Bitcoin as the best asset for diversification. Comparing the periods of high and low interest rates, according to the DCC-GARCH model, the mean pairwise conditional correlations between EWZ and Bitcoin, gold and bonds increased during the low-interest-rate period. Results for the BEKK model are mixed. The standard deviation of all assets from the DCC-GARCH model decreased during the low-interest-rate period. The BEKK model indicates the

\footnotetext{
3 Joesley Batista is a Brazilian businessman and CEO of JBS, one of the biggest global producers of animal protein. He was involved in a corruption scandal. On 05/17/2017 a secret conversation between Batista and then-President Michel Temer was made public. Batista said that was paying for the silence of Eduardo Cunha (former president of the Chamber of Deputies, the lower house of Brazil's Congress), who was in prison and belonged to Temer's centrist political party. Temer's resignation was expected by the market. The next market trading session was difficult for investors carrying long positions in equities.
} 
Table 12

Low-interest-rate period (08/01/2017 - 12/30/2019):

Statistics based on conditional correlations

\begin{tabular}{llrrrr}
\hline \multirow{4}{*}{ DCC-GARCH } & \multicolumn{1}{c}{ gold } & bond & BTC & GSCI \\
\cline { 2 - 6 } & mean & 0.0900 & 0.1509 & 0.0353 & 0.2826 \\
& std. dev & 0.0461 & 0.0335 & 0.0313 & 0.0248 \\
& min & -0.0061 & 0.0840 & -0.0310 & 0.2254 \\
BEKK & max & 0.1918 & 0.2341 & 0.1011 & 0.3355 \\
\cline { 2 - 6 } & mean & 0.0632 & 0.0729 & 0.0197 & 0.2601 \\
& std. dev & 0.0867 & 0.1248 & 0.1285 & 0.0951 \\
& min & -0.2604 & -0.3222 & -0.5245 & -0.1508 \\
& max & 0.2554 & 0.5801 & 0.6262 & 0.6593 \\
\hline
\end{tabular}

Table 13

High-interest-rate period (01/17/2014 - 12/29/2016): Statistics based on conditional correlations

\begin{tabular}{llrrrr}
\hline \multirow{4}{*}{ DCC-GARCH } & \multicolumn{1}{c}{ gold } & bond & BTC & GSCI \\
\cline { 2 - 6 } & mean & 0.0118 & 0.1036 & -0.0496 & 0.3658 \\
& std. dev & 0.0671 & 0.0864 & 0.0596 & 0.0707 \\
& min & -0.1696 & -0.1494 & -0.3498 & 0.1515 \\
BEKK & max & 0.2254 & 0.2982 & 0.0839 & 0.5358 \\
\cline { 2 - 6 } & mean & 0.0300 & 0.0910 & -0.0168 & 0.2951 \\
& std. dev & 0.0717 & 0.1316 & 0.1485 & 0.1308 \\
& min & -0.2502 & -0.2294 & -0.5245 & -0.1508 \\
& max & 0.2554 & 0.5801 & 0.6262 & 0.2554 \\
\hline
\end{tabular}

same, except for gold, which changed slightly in the opposite direction. Regarding the standard deviation, the same conclusion as the domestic case can be inferred for foreign investors in their allocations.

Finally we use the entire series encompassing the period from 01/17/2014 to 12/30/2019. The results are in Table 14. Based on the DCC-GARCH model, as in both previous analyses, shorting (buying) the GSCI is the best strategy for long (short) positions in the EWZ, followed by the fixed-income asset. Bitcoin is the most useful asset for diversification. The BEKK model indicates the same conclusions.

Figure 2 exhibits the conditional correlation series between each asset and the EWZ. Although less pronounced, the effect of "Joesley Day" can be noted, mainly in the GSCI and Bitcoin series. This is the same disruption observed in local currency and is related to the abrupt movement that occurred. 
Table 14

Entire sample period (01/17/2014 - 12/30/2019): Statistics based on conditional correlations

\begin{tabular}{|c|c|c|c|c|c|}
\hline & & gold & bond & BTC & GSCI \\
\hline \multirow[t]{4}{*}{ DCC-GARCH } & mean & 0.0370 & 0.1102 & -0.0152 & 0.3208 \\
\hline & std. dev & 0.0501 & 0.0647 & 0.0478 & 0.0568 \\
\hline & $\min$ & -0.0999 & -0.0871 & -0.1920 & 0.2095 \\
\hline & $\max$ & 0.1834 & 0.2454 & 0.0930 & 0.4726 \\
\hline \multirow[t]{4}{*}{ BEKK } & mean & 0.0235 & 0.0874 & -0.0011 & 0.2846 \\
\hline & std. dev & 0.1034 & 0.1600 & 0.1667 & 0.1390 \\
\hline & $\min$ & -0.3017 & -0.3531 & -0.6431 & -0.1843 \\
\hline & $\max$ & 0.3316 & 0.5974 & 0.6262 & 0.6969 \\
\hline
\end{tabular}

Figure 2

\section{Conditional correlations in U.S. dollars from DCC-GARCH for} $01 / 17 / 2014$ to $12 / 30 / 2019$

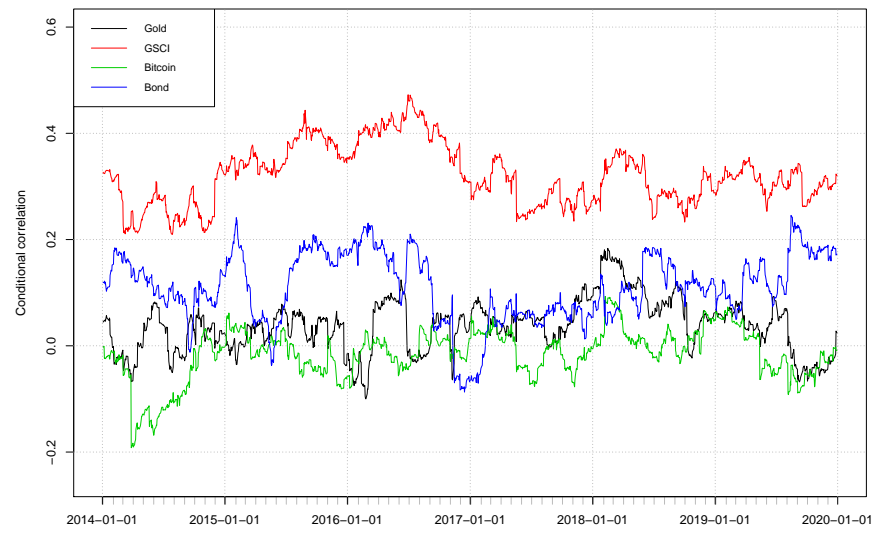

\section{Conclusion}

In this paper we analyze the conditional correlation between the Brazilian equity index and different asset classes traded in domestic and U.S. dollars during periods of high and low interest rates in Brazil. We use the BEKK and DCC-GARCH models to estimate the conditional correlations.

From the perspective of an investor trading domestic assets, we find that the exchange rate (R\$/US\$) had the highest absolute mean value of conditional correlation with the equity index, followed by gold. They were neg- 
atively correlated with the equity index. Hence, a long (short) position in equities was better hedged by assuming a long (short) position in the exchange rate and/or gold. Both were robust assets to hedge during the lowand high-interest-rate periods. The local long-term fixed-income asset was the third-best asset to hedge domestic equity positions. Due to the positive correlation with equities, to hedge long (short) equity positions one would short (buy) the fixed-income asset. During the low-interest-rate period, the conditional correlation series presented lower standard deviation, probably due to greater confidence of investors regarding macroeconomic policies.

From the perspective of an investor trading in U.S. dollars, the best strategy to hedge long (short) positions in the EWZ was to short (buy) the GSCI, followed by the fixed-income asset. The standard deviation of the conditional correlation series decreased during the period of low interest rates (except for gold in the BEKK model). This is the same conclusion observed in local currency analysis. In general, the series of conditional correlations estimated by the BEKK and DCC-GARCH models presented similar results for the mean and small differences for the standard deviations.

\section{Acknowledgements}

We would like to thank Prof. Marcelo Fernandes (the editor) and an anonymous referee for their valuable comments. All remaining errors and omissions are our sole responsibility.

\section{References}

Afonso, J. R., Araújo, E. C. and Fajardo, B. G. (2016). The role of fiscal and monetary policies in the Brazilian economy: Understanding recent institutional reforms and economic changes, Quarterly Review of Economics and Finance 62: 41-45.

Akaike, H. (1974). A new look at the statistical model identification, IEEE Transactions on Automatic Control 19(6): 716-723.

B3 (2020). History of investor's participation in the Brazilian stock market. Accessed: 2020-04-04.

URL: http://www.b3.com.br/pt_br/market-data-e-in dices/servicos-de-dados/market-data/consultas/me rcado-a-vista/historico-pessoas-fisicas/

Baba, Y., Engle, R. F., Kraft, D. F. and Kroner, K. F. (1990). Multivariate simultaneous generalized ARCH. Manuscript, University of California, San Diego, Department of Economics. 
Baur, D. G. and Lucey, B. M. (2010). Is gold a hedge or a safe haven? An analysis of stocks, bonds and gold, Financial Review 45(2): 217-229.

Bollerslev, T. (1986). Generalized autoregressive conditional heteroskedasticity, Journal of Econometrics 31: 307-327.

Borio, C. E. and Hofmann, B. (2017). Is monetary policy less effective when interest rates are persistently low? BIS Working paper.

Bouri, E., Molnár, P., Azzi, G., Roubaud, D. and Hagfors, L. I. (2017). On the hedge and safe haven properties of Bitcoin: Is it really more than a diversifier?, Finance Research Letters 20: 192-198.

Chang, C., McAleer, M. and Tansuchat, R. (2013). Modelling long memory volatility in agricultural commodity futures returns, Annals of Financial Economics 7(02).

Cheng, I.-H. and Xiong, W. (2014). Financialization of commodity markets, Annual Review of Financial Economics 6(1): 419-441.

Creti, A., Joëts, M. and Mignon, V. (2013). On the links between stock and commodity markets' volatility, Energy Economics 37: 16-28.

Dyhrberg, A. H. (2016). Hedging capabilities of Bitcoin. Is it the virtual gold?, Finance Research Letters 16: 139-144.

Engle, R. (2002). Dynamic conditional correlation: A simple class of multivariate generalized autoregressive conditional heteroskedasticity models, Journal of Business \& Economic Statistics 20(3): 339-350.

Engle, R. F. and Kroner, K. F. (1995). Multivariate simultaneous generalized ARCH, Econometric Theory 11(1): 122-150.

Erb, C. B. and Harvey, C. R. (2006). The strategic and tactical value of commodity futures, Financial Analysts Journal 62(2): 69-97.

Ferreira, D. M. and De Mattos, L. B. (2014). The contagion effect of the subprime crisis in the Brazilian stock market, Procedia Economics and Finance 14: 191-200.

Glosten, L., Jagannathan, R. and Runkle, D. (1993). On the relation between the expected value and the volatility of the nominal excess return on stocks, Journal of Finance pp. 1779-1801. 
Gorton, G. and Rouwenhorst, K. G. (2006). Facts and fantasies about commodity futures, Financial Analysts Journal 62(2): 47-68.

Gouriéroux, C. (2012). ARCH Models and Financial Applications, Springer Science \& Business Media.

Klein, T., Thu, H. P. and Walther, T. (2018). Bitcoin is not the New Gold - A comparison of volatility, correlation, and portfolio performance, International Review of Financial Analysis 59: 105-116.

Lombardi, M. J. and Ravazzolo, F. (2016). On the correlation between commodity and equity returns: Implications for portfolio allocation, Journal of Commodity Markets 2(1): 45-57.

Manera, M., Nicolini, M. and Vignati, I. (2013). Financial speculation in energy and agriculture futures markets: A multivariate GARCH approach, Energy Journal 34(3): 55-81.

Marçal, E. F. and Valls Pereira, P. L. (2009). Testing the hypothesis of contagion using multivariate volatility models. Available at SSRN 1373152.

URL: https://dx.doi.org/10.2139/ssrn.1373152

McAleer, M., Chan, F., Hoti, S. and Lieberman, O. (2008). Generalized autoregressive conditional correlation, Econometric Theory 24(6): 15541583.

Nelson, D. (1991). Conditional heteroskedasticity in asset returns: A new approach, Econometrica 59(2): 347-370.

Olson, E., Vivian, A. and Wohar, M. E. (2017). Do commodities make effective hedges for equity investors?, Research in International Business and Finance 42: 1274-1288.

Sadorsky, P. (2014). Modeling volatility and correlations between emerging market stock prices and the prices of copper, oil and wheat, Energy Economics 43: 72-81.

Schwarz, G. E. (1978). Estimating the dimension of a model, Annals of Statistics 6(2): 461-464.

Tse, Y. K. and Tsui, A. K. C. (2002). A multivariate generalized autoregressive conditional heteroscedasticity model with time-varying correlations, Journal of Business \& Economic Statistics 20(3): 351-362. 
Vartanian, P. R. (2020). Volatility transmission between commodities and Ibovespa in the period 2000-2016: Is there a possibility of diversification?, International Economics and Economic Policy pp. 1-19. 


\section{A. Appendix}

In this appendix we present the general diagonal BEKK $(p, q)$ model and also the variance equations for the univariate GARCH models used in the first step of the DCC-GARCH estimation.

(i) The BEKK $(p, q)$ model is defined as:

$$
\boldsymbol{H}_{t}=\boldsymbol{C}^{\top} \boldsymbol{C}+\sum_{i=1}^{q} \boldsymbol{A}_{i}^{\top} \boldsymbol{\varepsilon}_{t-i} \boldsymbol{\varepsilon}_{t-i}^{\top} \boldsymbol{A} i+\sum_{j=1}^{p} \boldsymbol{B}_{j}^{\top} \boldsymbol{H}_{t-j} \boldsymbol{B}_{j},
$$

where the details of the terms involved are in the text.

(ii) $\operatorname{GARCH}(\mathrm{p}, \mathrm{q})$ model:

$$
h_{t}=\omega+\sum_{j=1}^{q} \alpha_{j} \varepsilon_{t-j}^{2}+\sum_{j=1}^{p} \beta_{j} h_{t-j}
$$

where the parameters must satisfy $\omega>0, \alpha_{j}>0$ and $\beta_{j}>0$ to guarantee that $h_{t}>0$.

(iii) $\operatorname{EGARCH}(\mathrm{p}, \mathrm{q})$ model:

$$
\ln h_{t}=\omega+\sum_{j=1}^{q} \alpha_{j} z_{t-j}+\gamma_{j}\left(\left|z_{t-j}\right|-E\left(\left|z_{t-j}\right|\right)\right)+\sum_{j=1}^{p} \beta_{j} \ln h_{t-j}
$$

where the parameters $\alpha_{j}, \gamma_{j}$ and $\beta_{j}$ do not need any restrictions to ensure that $h_{t}$ is non-negative.

(iv) GJR (p,q) model:

$$
h_{t}=\omega+\sum_{j=1}^{q}\left(\alpha_{j} \varepsilon_{t-j}^{2}+\gamma_{j} I_{t-j} \varepsilon_{t-j}^{2}\right)+\sum_{j=1}^{p} \beta_{j} h_{t-j}
$$

where $I$ is an indicator function that takes value 1 for $\varepsilon \leq 0$ and 0 otherwise. To ensure positiveness of $h_{t}$, we must have $\omega>0,2 \alpha+\gamma>$ 0 and $\beta>0$. 